\title{
Blessings in Disguise: Yoga and Meditation during Corona Lockdown
}

\author{
Anjali Ambadas Vagga ${ }^{1}$, Archana Janardan Dhok ${ }^{2}$ \\ ${ }^{1}$ Department of Biochemistry, Jawaharlal Nehru Medical College, Datta Meghe Institute \\ of Medical Sciences (Deemed to Be University), Wardha, Maharashtra, India. \\ ${ }^{2}$ Department of Biochemistry, Jawaharlal Nehru Medical College, Datta Meghe Institute \\ of Medical Sciences (Deemed to Be University), Wardha, Maharashtra, India.
}

\section{ABSTRACT}

\section{BACKGROUND}

The word Yoga originates from the Sanskrit word "Yuj" means to attach, join, Yoke or "Yuj" Samadhi. Yoga asanas twist the internal organs, strengthen muscles and increases circulation. Breathing technique and meditation also release stress and improve immunity. Health is our wealth. This difficult time can be utilized for building physical and mental health. The rule of social distancing which has been in action is a great facility that provides natural support to immune system and to build the mental health. It also gives more time to be with your family and keep yourselves occupied with productive activities. The term "meditation" usually refers to a formal practice that can give peace to the mind and increase awareness of our conscious, our mind and our environment. Meditation in its many forms has been practiced over millions of years by diverse groups of people in many different traditions. Previously it was practiced in the East, eventually has spread into Western countries and is increasingly augmenting therapy. These days are very difficult to manage your mind. So, meditation is the only useful activity that helps to overcome such a bad situation (corona lockdown). One should do mindful meditation daily. Encourage kids, but do not force them to do these activities. This study found that due to meditation, there is reduction in oxygen consumption, decreased heart rate, decreased respiration rate, enhanced carbon dioxide elimination, reduced cortical hormone level, decreased blood lactate levels, and increased parasympathetic activity. An overall effect of meditation is that it provides nutrition to your mind and brain. Meditation is a blessing in disguise in such crucial time. Regular practice of yoga and meditation help us to improve our quality of life. The purpose of this article is to describe what yoga and meditation are, their practices and their effects on physical and mental health.
Corresponding Author: Dr. Anjali Ambadas Vagga, 102, Vastu-Vishaw Apartment, Dream Land City, Near Nagpur Bypass, Sawangi-442001, Wardha,

Maharashtra, India.

E-mail: anjalivagga@gmail.com

DOI: $10.14260 / \mathrm{jemds} / 2020 / 552$

How to Cite This Article:

Vagga AA, Dhok AJ. Blessings in disguise: yoga and meditation during corona lockdown. J Evolution Med Dent Sci 2020;9(35):2540-2544, DOI: $10.14260 /$ jemds/2020/552

Submission 27-05-2020,

Peer Review 22-07-2020,

Acceptance 29-07-2020,

Published 31-08-2020.

Copyright (C) 2020 JEMDS. This is an open access article distributed under Creative Commons Attribution License [Attribution 4.0 International (CC BY 4.0)]

\section{KEY WORDS}

Yoga, Meditation, Corona, Lockdown, Benefits 
Yoga is known to be as old as 8000 years. ${ }^{1}$ In the course of time, different yoga asanas have been devised which can restore and maintain health and can increase self-awareness and consciousness. The meaning of yoga is union. The word yoga is mentioned in a Sanskrit epic written in the second half of the $1^{\text {st }}$ Millennium BCE and is associated with the philosophical system presented in the yoga sutras of Patanjali with the chief aim of uniting the human spirit with divine spirit. ${ }^{2}$ Yoga is basically a spiritual discipline based on an extremely divine science, which focuses on bringing harmony between mind and body. It is an art and science of healthy living. Yoga brings peace not only to the body in the form of asanas, but to the mind and emotional wellbeing too. Weight loss is one of the beneficial effects of its regular practice. Regular practice of yoga calms down the mind and reduces stress and increases wellness.

This study found that due to meditation there is reduced oxygen consumption, decreased heart rate, decreased respiration rate, enhanced carbon dioxide elimination, reduced cortical hormone levels, decreased blood lactate levels and increased parasympathetic activity. An overall effect of meditation is that it provides nutrition to your mind and brain. Mindfulness is being aware of the present moment. During the global pandemic, initiating mindfulness and meditation practice is likely to complement therapies and is also a beneficial method to provide support in anxiety attacks. ${ }^{3}$

Surya namaskar includes 12 steps that makes half the cycle:

1. Pranam asana

2. Hasta uttanasana

3. Padahast asana

4. Ashwa sanchalanasana

5. Santolan asana

6. Padahast asana

7. Ashtanga namaskar asana

8. Bhujangasana

9. Adhomukhasvanasana

10. Ashwa sanchalanasana

11. Padahastasana

12. Hasta uttanasana.

\section{Immunity}

Yoga asanas twist the internal organs, strengthen the muscles and increase blood circulation. The breathing technique and meditation also releases stress and improves immunity. A few minutes of yoga everyday makes you feel fresh and energetic for a long period of time. The long deep breathing process makes one feel fresh and energetic and oxygenates the blood and brain. Regular practice of yoga improves your muscle tone and posture. Yoga asanas bring positive state of mind. Regular practice of yoga and meditation can increase integrations between physical and mental health. Some researchers suggested that yoga benefits physical and mental health. However, there is a lack of evidence due to less research work in this area. Yoga has the potential to be implemented as an alternate treatment to bring relative cost effectiveness and increase self-awareness of the body. 4 Adversities and psychological stress such as depression have divergent effects on the immune system; anti-viral immunity and resistance to infectious diseases. However, markers of inflammation and risk of inflammation associated diseases are increased.5,6
Is Corona Virus Lockdown Making You Anxious and Depressed?

American Heart Association signifies the role of meditation in cardiovascular disease. People living inside their homes due to the COVID-19 pandemic lockdown could benefit from yoga to boost immunity. Many people believed that yoga is just a posture, but it is not the truth. In fact, sufficient period of yoga and meditation practice helps to relieve or decrease the stress levels. Indian American cardiologist Ray suggested that when a person is in depression and anxiety, they have adverse effects physically and develop weak immunity towards viral infections. When we forced the students to isolate and stay at home in COVID-19 pandemic, it created anxiety and depression in some cases. Ray said that when the human body is exposed to corona virus, the body will produce direct antibodies which can react to protect the immune system.

\section{Enhanced Blood Circulation with Yoga}

Sun salutation or Surya Namaskar is the best set of yoga asana. This will reward you with physical and mental strength, give you command over your body, enhance blood circulation, calm your mind, balance your energy levels and bring peace to your consciousness.

\section{Yoga and Meditation for Mind-body and Health}

Many participants have reported that after yoga and meditation, there is positive effect on their physical and mental health. A research article published in Frontiers in Human Neuroscience investigates the effects of yoga and meditation on brain derived neurotropic factor (BDNF), the activity on the hypothalamic pituitary adrenal (HPA) effects and inflammatory markers. 38 participants practising 3months of intense yoga and meditation retreat were assessed before and after the intervention. Researchers found that the practices positively impacted BDNF signalling, the cortisol awakening response (CAR) and immunological markers and in addition improved subjective wellbeing. ${ }^{7}$

\section{Role of Yoga for Healthy Life}

Regular practising of pranayama, yoga and meditation gives natural immunity by lowering stress hormones in your body. Apart from this, it conditions the lungs and respiratory tract, stimulates the lymphatic system by removing toxins from the body and ensures optimal functioning of organs. It is the time when you can dive deep in your meditation and pranayama asana. This is the technique that helps to build your physical and mental health. ${ }^{8}$ Health is wealth; this difficult time can be utilized for building physical and mental health. ${ }^{9}$ Regular practice of yoga and meditation helps us to improve the quality of our life.

\section{Role of Yoga in Metabolic Syndrome}

Yoga practitioners have increased biological variation compared to non-yoga practitioners and patients with metabolic syndrome-decreased oxygen uptake during the basal conditions; and enjoy quicker recovery from stress. Consumption of oxygen in metabolic syndrome patients shows significantly blunted post-stress recovery and diminished metabolic adaptability. 10 


\section{How to Manage Depression and Anxiety}

Poor mental health conditions including stress and depression are known to increase the risk of acute respiratory infections. ${ }^{11}$ Increasing numbers of corona virus infections and mortality triggers stress and anxiety. This is due to isolation and depression because of mandatory social distancing measures. Nonetheless, the rule of social distancing that has been in action nowadays is a great facility that provides natural support to immune system and build mental health. It also gives more time to be with your family and keep yourselves occupied with productive activities, including group activities with your family members such as playing cards, listening to music, singing, cooking and sharing your thoughts etc.

\section{How Meditation is Useful to Cope With COVID-19}

Through practicing awareness of your thoughts and feelings, you will be able to know better when to stop and take a moment for yourself. ${ }^{9}$ If you can find a quiet place anywhere, you can start meditating at any time and it does not require any equipment and practicing it is not time bound. When we are practicing meditation regularly, it gets easier and also results in healthier mind and body. ${ }^{12}$ Physical isolation and the fear of uncertain future can lead to strange feelings or emotions and high anxiety. We cannot control all situations in life but can change our way of thinking. Yoga helps to balance emotions in difficult times. About 50,000 to 90,000 thoughts are rushing through our mind at any instance. Our brain is drained by overworking and multi-functioning and switches to an auto pilot mode when actions are taken without thinking about them consciously. In the long term, this can lead to superficial focus, increased stress, insomnia and other complications. Meditation helps us to control emotions in bad times. Meditation can be performed in a million ways depending on what suits your personality, goal and preferences. ${ }^{13}$

\section{Different Ways to Practice Yoga and Meditation In Corona Lockdown}

As you can see, there are so many yoga asana YouTube videos available on the internet. Various yoga techniques available on YouTube will help individuals to do yoga and meditation during lockdown and self-quarantine.

\section{Private Yoga Teacher Consultation}

When you are connected with a yoga teacher through the internet, you can feel the virtual presence of many other students. In private consultation, there is increased teacher to student attention.

\section{Self-Practice}

Self-practice is not an easy job it requires time management and discipline. If you find a silent place, you can meditate easily. Beginners have difficulty in controlling their thoughts, but when they meditate regularly it becomes easier and a healthier mind and body is attained.13 These are very difficult days to manage your mind, so meditation is the only regime to overcome such bad situations; you need to do mindful meditation daily. Encourage kids, but do not force them to do these activities. There are various meditation methods that are easily available online. This is an unprecedented situation at least for the new generation, not only for an individual or a nation but for the entire humanity. Besides the fear of infection, people have been confined to their homes. How would spirituality help to overcome from present situation? Protect yourself and support others. Assist others in their time of need to benefit both the person receiving support and giving. Minimize watching, reading or listening to news about COVID-19 that makes you feel anxious or distressed. Take practical steps to prepare your plans, protect yourself and the loved ones. Collect information from WHO website and local health member forums in order to help you distinguish facts from rumours, as facts can help to minimize fears. ${ }^{14}$

\section{Physiological Effects of Meditation}

- Decreased heart rate

- Decreased cortical hormone levels

- $\quad$ Effect on blood pressure

- Effect on metabolism and respiration

- $\quad$ Effect on skin

\section{Decreased Heart Rate}

Some researchers observed that heart rate slows down during meditation. Meditation has a relaxing response and decreases heart rate. 15

\section{Effect on Hypertension}

Those who are regularly practicing meditation show physiological variation like decrease in blood pressure. ${ }^{16}$

\section{Effect on Metabolism}

Some researchers observe that during meditation there is decreased oxygen utilization, increased carbon dioxide elimination and decreased respiration rate. ${ }^{14,17}$ Some researchers have showed that during regular practice of meditation, there is reduced oxygen consumption, decreased heart rate, decreased respiration rate, enhanced carbon dioxide elimination, reduced cortical hormone levels, decreased blood lactate levels and increased parasympathetic activity. ${ }^{18}$

\section{PSYCHOLOGICAL EFFECTS OF MEDITATION}

\section{Increased Memory}

Jedrezak et $\mathrm{al}^{19}$ observed that several months of regular practice of meditation have increased performance in nonverbal intelligence tests. Other researchers also reported that there is improvement in cognitive abilities due to meditation. There are effects of transcendental meditation on the performance of some cognitive psychological tests. ${ }^{20}$

\section{More Creativity and Self-realization}

Mixed type of results has been reported by few researchers regarding creativity and meditation. Some of them observed positive co-relation between meditation and creativity. ${ }^{21}$ 


\section{Role of Yoga on Mental Health}

There is disturbed mental health due to COVID-19 lockdown. Stress and depression increase the risk for respiratory infections too. Pranayama and meditation are measures of mental health. Pranayama improves respiratory system..$^{22}$ Meditation is effective in reducing inflammation marker and also influences markers of virus specific immune response. Both yoga and meditation are powerful tools for prevention and boosts recovery from corona infections. ${ }^{8}$ Researchers suggest that several measures may be useful to reduce the risk of COVID-19 infection and can complement therapy along with treatment. ${ }^{23}$

\section{Healing Power of Meditation}

With regular practices of meditation, significantly higher levels of positive effects and low levels of anxiety and increased happiness in our body language can be achieved.24 "Medical Yoga Therapy" is referred by physicians. Powerful and effective yoga therapy serves a patient with physical and mental challenges. Yoga therapy is safe and effective as it has healing power in children too. ${ }^{25}$ A study reported that 42 participants completed stress reduction programme in which they learned yoga techniques and meditation. ${ }^{26}$ During such a critical moment meditation is a blessing in disguise. Practice meditation every day and enjoy its rich benefits. It can help prevent coronary heart disease, heart attack and re-infarction if practiced regularly. ${ }^{27}$ Meditation provides nutrition to your mind and brain. We have a lot of stored energy in our body, but we never use it. When we meditate it helps us to utilize the stored energy.

Financial or Other Competing Interests: None.

\section{REFERENCES}

[1] Sovik R. The science of breathing--the yogic view. Prog Brain Res 2000;122:491-505.

[2] William M. A Sanskrit English dictionary. Delhi, India: Gyan Books Pvt Ltd 1899.

[3] Behan C. The benefits of meditation and mindfulness practices during times of crisis such as COVID-19. Ir J Psychol Med 2020:1-3.

[4] Büssing A, Michalsen A, Khalsa SBS, et al. Effects of yoga on mental and physical health: a short summary of reviews. Evid Based Complement Alternat Med 2012;2012:1-7.

[5] Irwin MR, Cole SW. Reciprocal regulation of neural and innate immune systems. Nat Rev Immunol 2011;11(9):625-32.

[6] Miller GE, Chen E, Sze J, et al. A functional genomic fingerprint of chronic stress in human: blunted glucocorticoid and increased NF-kappaB signaling. Biol Psychiatry 2008;64(4):266-72.

[7] Chan BR, Goodman MS, Peterson CT, et al. Yoga, meditation and mind-body health: increased BDNF, cortisol awakening response and altered inflammatory markers expression after 3-month yoga and meditation retreat. Front Hum Neurosci 2017;11,315.
[8] Morgan N, Irwin MR, Chung M, et al. The effects of mindbody therapies on immune system: meta-analysis. PLoS One 2014;9(7):e100903.

[9] Substance Abuse and Mental Health Services Administration, Results from the 2013 National Survey on Drug Use and Health: Mental Health Findings, NSDUH Series H-49, HHS Publication No. (SMA) 14-4887. Rockville, MD: Substance Abuse and Mental Health Services Administration, 2014. p. 13.

[10] Taygi A, Cohen M, Reece J, et al. An exporative study of metabolic response to mental stress and yoga practices in yoga practitioners, non-yoga practitioners and individual with metabolic syndrome. BMC Complement Altern Med 2014;14:445.

[11] Maxwell L, Barrett B, Chase J, et al. Self-reported mental health predicts acute respiratory infection. WMJ 2015;114(3):100-4.

[12] Hussain D, Bhushan B. Psychology of meditation and health: present status and future directions. International Journal of Psychology and Psychological Therapy 2010;10(3):439-51.

[13] Desbordes G, Gard T, Hoge EA, et al. Moving beyond mindfulness: defining equanimity as an outcome measure in meditation and contemplative research. Mindfulness 2015;6(2):356-72.

[14] Sudsuang R, Chentanez V, Veluvan K. Effect of Bhuddist meditation on serum cortisol and total protein levels. blood pressure, pulse rate, lung volume and reaction time. Physiol Behav 1991;50(3):543-8.

[15] Bono J. Psychological assessment of transcendental meditation. In: Shapiro DH, Walsh RN, eds. Meditation: classic and contemporary perspective. New York: Aldine 1984.

[16] Sear P, Raeburn JM. Meditation training and essential hypertension: a methodological study. J Behav Med 1980;3(1):59-71.

[17] Kesterson MA. Changes in respiratory patterns and control during practice of the transcental meditation technique. Dissertation Abstract International 1986;47:4337.

[18] Danucalov M, Simoes R. Neurofisiologia da meditaçao. Sao Paulo: Phorte 2006.

[19] Jedrczak A, Toomey M, Clements G. The TM-Sidhi program, age and brief tests of perceptual-motor speed and nonverbal intelligence. J Clin Psychol 1986;42(1):161-4.

[20] Verma IC, Jayashankarappa BS, Palani M. Effect of transcendental meditation on the performance of some cognitive psychological test. Indian J Med Res 1982;76 Suppl:136-43.

[21] 0'Haire TD, Marcia JE. Some personality characteristics associated with ananda marga meditators: a pilot study. Perceptual and Moter Skills 1980;51(2):447-52.

[22] Abel AN, Lloyd LK, Williams JS. The effects of regular yoga practice on pulmonary function in healthy individual: a literature review. J Altern Complement Med 2013;19(3):185-90.

[23] Tillu G, Chaturvedi S, Chopra A, et al. Public health approach of ayurveda and yoga for COVID-19 prophylaxis. J Altern Complement Med 2020;26(5):360-4.

[24] Beauchamp-Turner DL, Levinson DM. Effects of meditation on stress, health, and affect. Medical Psychotherapy: An International Journal 1992;5:123-31. 
[25] Stephens I. Case report: the use of medical yoga for adolescent mental health. Complementary Therapies in Medicine 2019;43:60-5.

[26] Nick Lowndes. Health and medicine learning not to fear. The Harvard Gazette 10/2019.
[27] Khobragade Y, Abas ABL, Ankur B, et al. Meditation as primary intervention strategy in prevention of cardiovascular disease. International Journal of Research in Medical Sciences 2016;4(1):12-21. 